\title{
Empirical Research of College Students' Alternative Frameworks of Particle Mechanics
}

\author{
Hongmei Wang \\ Department of Physics, Dezhou University, Dezhou 253023, China \\ Tel: 86-534-8985-398Ｅ-mail: whm_2327@126.com
}

The research is financed by the "Study on the Applied Talent Cultivation Mode of Chinese Colleges" of "Eleventh Five-Year" National Project of Applied Undergraduate Colleges (No. FIB070335-A3-08). (Sponsoring information)

\begin{abstract}
Based on the constructive theory, about 300 college students of grade 05 of the electronic information specialty of Dezhou University are surveyed for their alternative frameworks of particle mechanics in college physics in this article. In the survey, the questionnaires are used to find out college students' alternative frameworks, and the character and formation causes of alternative frameworks are analyzed. Finally, according to the conclusions of survey and experiment research, a few advices in the teaching of college physics are proposed.
\end{abstract}

Keywords: Force concept inventory (FCI), Alternative frameworks, Teaching strategies

\section{Introduction}

Survey researches and teaching practices indicate that one important thinking obstacle exists when students profoundly understand the concept of physics, i.e. when students contact new knowledge, they always try to understand them by old knowledge structure and thinking mode, even modify the connotation of new knowledge to adapt old knowledge structure and thinking mode, so new knowledge and old knowledge will be mixed to generate various ideas deviating from scientific concepts, which are called as alternative frameworks in the teaching theory. Foreign and domestic teaching staffs have studied students' alternative frameworks largely (Tan, 1996, P.53 \& David P. Maloney, 2001, P.S12-S23 \& Ye, 2000, P.78 \& Xiang, 2001 \& Du, 2002, P.45).

By questionnaire testing of freshmen's electric information specialty before and after learning, students' alternative frameworks can be found in the learning of the concepts of particle mechanics, and the characters and formation causes of college students' alternative frameworks are analyzed, which can provide advices for the teaching of college physics.

\section{Research objects and methods}

Research samples are about 300 students including freshmen and sophomores of the electric information specialty of the department of physics of Dezhou University. Freshmen just finish the learning of high school physics, and favorably pass the college entrance exam after several reviews, but they didn't study the college physics. In the October of 2005, the testing of the second stage is implemented, and the testing subjects include freshmen and sophomores, and freshmen have complete the learning of part content of particle mechanics of college physics, and sophomores who have learning the college physics for one year are studying the subsequent course. In the questionnaire, the current "FCI" designed by physical teaching staff, David Hestenes, in 1992 (David Hestenes, 1992, P.41-158) is adopted, and the statistical software of SPSS11.0 is utilized to solve the Pearson product moment correlation coefficient of two times effective scores of questionnaires, and this coefficient denotes the alternate-form reliability (i.e. the coefficient of equivalence), and $r_{t t}=0.732$. According to the requirements of psychometrics, the reliability score of questionnaire exceeds 0.7 , i.e. this questionnaire is reliable and acceptable. Then the software of SPSS11.0 is utilized to implement the difference test and the statistical analysis.

\section{Data statistics}

3.1 Data statistics of difference test of testing result

The data statistics of the result of difference testing are seen in Table 1 to Table 5.

\subsection{Statistical result of the error rate of seven sorts of question}

Convenient for statistics and descriptions, 144 options in the testing are classified into seven sorts to respectively compute the error rates according to the design of FCI. 


\section{Analysis and discussion of the difference test of testing result}

From Table 1, before freshmen study the college physics, the average testing scores of two classes are almost equal, and the significant difference doesn't exist by the test of Z, which indicates freshmen's understandings about the establishment of the concepts in the particle mechanics are on same level. Therefore, one class is randomly selected in two classes as the experimental class, and the other class is the control class (1), and in the October of 2005, the experimental class, the control class (1) and the sophomores (the control class (2)) are tested after learning.

From Table 2, before freshmen study the college physics, for the average score of the particle mechanics testing, male students' is higher than female students', and the significant difference exists, which indicates that students' understandings about the concepts in the particle mechanics have been improved, but male students' enhancement effect is obviously higher than female students'.

From Table 3, after the control class adopts the teaching strategy of the concept transform theory, for same one test questions about the mechanic concept, the average scores of testing are obviously higher than the scores before learning, and the extremely significant difference exists by the test of $\mathrm{Z}$.

From Table 4, after the control class adopts the teaching strategy of the concept transform theory, the average testing score of the experimental class is obviously higher than the control class (1), and the extremely significant difference exists by the test of $Z$, which indicates that teaching strategy of the concept transform theory is effective to establish and understand the basic concepts about mechanics.

From Table 5, the average testing score of the experiment class obviously exceeds the score of the control calls (2), and the extremely significant difference exists by the test of Z. From Table 5 and Table 4, the average testing score of the control class (2) is lower than the average testing score of the control class (1).

From Table 1 and Table 4, the average testing scores of the control class before learning and after learning respectively are 81.2558 and 81.3719 , and the difference is small, which indicates that the traditional teaching method could little transform students' alternative frameworks. But from Table 4, because of the difference of teaching methods, the average testing score of the control class after learning obviously exceeds the score of the control class, and the extremely significant difference exists by the test of $Z$, which can prove that the effect of transforming students' alternative frameworks by the concept transform strategy is better than the traditional teaching method.

\section{Analysis result of alternative frameworks}

\subsection{Main alternative frameworks}

According to the error rate statistics of sever sorts of question, following college students' alternative frameworks can be discovered.

(1) It is not universal that the acting force and the reacting force in the law of action and reaction are always equal for some students.

(2) The Newton First Law can not been correctly utilized to analyze the movement of objects.

(3) The light object with same speed can fly farther than the heavy object at the same altitude.

(4) Function effect of instant force would be falsely transformed into the effect of durative force.

(5) The understanding about the relationships among $\vec{F}, \vec{a}$ and $\Delta \vec{v}$ is not deep and intensive.

(6) The ascending ability of the inertia is often prolonged when analyzing problems.

(7) The work of acting force and the work of reacting force are equal.

\subsection{Causes of alternative frameworks}

\subsubsection{Improper analogy and reasoning of life experiences perceived in special conditions}

Students' accumulated daily life experiences are generated in special conditions, so when they fall across physical phenomena they can not directly perceive or they are difficult to perceive, they will always associate some similar apperceiving experiences in the past for comparison and reasoning by recollection, and these comparison and reasoning become into rotes, and even some students would not think but directly use these past knowledge when they encounter similar physical phenomena in the past daily life experiences.

5.2.2 False opinions formed by the perception of individual non-essential phenomena

A phenomenon is the exterior association and the surface character of material movements, and it is the exterior 
representation of things (Xiao, 1989, P.34), and it has characters such as individuality and unilateralism, which could easily cover the essential and induce feints. Because students' cognition always starts from the observation of phenomenon, and individual surface with strong stimulation function will leave profound traces, so when students observe physical phenomenon, they only grasp the non-essential character but ignore the interior association, and the physical phenomenon can not be completely analyzed. For example, because students often observe that the friction force always blocks the movement of objects, so they will think that the friction force always makes negative works.

\subsubsection{Causes from students' subjective cognitive structure}

The occurrence of alternative frameworks partly comes from students' subjective cognitive structure, and some students lack in "meaningful learning", so these students would certainly know the learned physical concepts superficially, but the theory of psychology tells us that the "resolvability" among blurry physical concepts is very low, and the interference will occur among them, and the so-called "negative transfer" will be formed in learning. For example, students would confuse the rotation of rigid body with the level movement of object, and regard the rotation balance as the balance of two forces.

\subsubsection{Causes from teachers}

In the situation of teaching reform, though the teaching modes have been improved, but the traditional teaching modes such as teachers prelect and students record, teachers emphasize knowledge contents and necessary guidance for students' good thinking mode, teachers more emphasize result than process, teachers pay attention to students' learning process not enough, teachers would not admit students' alternative frameworks or students' alternative frameworks have not be emphasized enough, and few of them will actively investigate students' "alternative frameworks" are still the mainstream. Even some teachers also have some alternative frameworks, just as students" "alternative frameworks" can not be transformed, and the traditional concepts are difficult to be transformed in some teaching staffs' brains.

\section{Teaching revelations of transforming alternative frameworks}

By data analysis and teaching experiment, in the physical teaching, to emphasize the concept teaching and effectively implement the transformation of alternative frameworks, following aspects should be noticed.

(1) Before instructing physical concepts to students, teachers must first correctly understand and grasp scientific physical concepts, try to some alternative frameworks in their cognitive structure, continually refresh relative concepts, and remove the interference sources of students' alternative frameworks.

(2) Teachers should fully investigate and know their students, and make teaching plans aiming at students' "alternative frameworks", and select and implement one effective teaching strategy to help students to implement the "concept conversion". From the data statistics in the article, it is obvious that the effect of implementing the teaching method of the concept conversion strategy to transform students' alternative frameworks is better than traditional teaching method.

(3) Emotion is a kind of attitude experience generated by whether the subjective things accord with people's requirements in the cognition process, and it is a necessary non-intelligent factor to compose students' psychological quality in the learning activity, and though it doesn't directly participate in described cognition activity, but it can organize or disorganize students' cognition process, and influence the intelligent activity (Li, 1999, P.56). Good emotion can not only "activate" students' intelligence, but make students to do their level best, conquer difficulties, and achieve appointed target, so good emotion is the spirit drive to convert alternative frameworks, and teachers should establish good teaching atmosphere.

(4) The function of experiments should be fully exerted. Because students' alternative frameworks come form the accumulation of daily life experiences and the stimulation and interference of nonessential phenomena, the physical experiments with pertinence and prominent essential could offer extensive perceived materials, and generate stronger apperception gravitation. Therefore, teachers should communicate with experimental teachers in time, and apply physical experiments to promote students to change their original concepts, drive the scientific revolution and convert alternative frameworks, and except for that, teachers should also pay attention to the important function of the classroom demonstration experiment to transform alternative frameworks.

\section{References}

David Hestenes, Malcolm and Gregg Swackhamer. (1992). Force Concept Inventory. The physics Teacher. No.30(3). P.41-158.

David P. Maloney, Thoms L. O’Kuma, Curtis J. Hieggelke and Alan Van Heuvelen. (2001). Surveying students' 
conceptual knowledge of electricity and magnetism. Am.J.Phys.Suppl. No.69(7). P.S12-S23.

Du, Junyi. (2002). Primary Research of High School Students' Alternative Frameworks of Physics Learning. Physics Teacher. No.6. P.45.

Li, Hongyu \& He, Yisu. (1999). Learning Dynamics. Wuhan: Hubei Educational Press. P.56.

Tan, Shusheng. (1996). Analysis of Physics Education Reforms of Various Countries. Shanghai: Shanghai Translation Publishing House. P.53.

Xiang, Fenghua. (2001). Study on the High School Students' Cognitive Development of Physics Learning. Thesis of the Education Master Specialty Degree of Beijing Normal University. No.5.

Xiao, Qian. (1989). Principle of Dialectical Materialism. Beijing: People’s Education Press. P.34.

Ye, Weidong. (2000). Knowing Students' Cognitive Structure is the Important Premise of Teaching: Survey of Junior High School Students' Learning of Electromagnetism Concept. Thesis of the Education Master Specialty Degree of Beijing Normal University. No.12. P.78.

Table 1. Test result of freshman students (before learning)

\begin{tabular}{|c|c|c|c|c|c|c|}
\hline Class & $\begin{array}{c}\text { Amount of } \\
\text { students (n) }\end{array}$ & Average scores $(\bar{x})$ & $\begin{array}{c}\text { Standard } \\
\text { difference }(\sigma)\end{array}$ & Value of $Z$ & Value of $\mathrm{P}$ & $\begin{array}{c}\text { Significance (double } \\
\text { sides) }\end{array}$ \\
\cline { 1 - 4 }$(1)$ & 67 & 82.09 & 7.84 & \multirow{2}{*}{$0.68<1.96$} & $\mathrm{p}>0.05$ & $\begin{array}{c}\text { Without significant } \\
\text { difference }\end{array}$ \\
\cline { 1 - 3 } & 136 & 81.27 & 9.25 &
\end{tabular}

Table 2. Test result of freshman male and female students (before learning)

\begin{tabular}{|c|c|c|c|c|c|c|}
\hline Sex & $\begin{array}{c}\text { Amount of } \\
\text { students } \\
(\mathrm{n})\end{array}$ & $\begin{array}{c}\text { Average } \\
\text { scores }(\bar{x})\end{array}$ & $\begin{array}{c}\text { Standard } \\
\text { difference }(\sigma)\end{array}$ & Value of $Z$ & $\begin{array}{c}\text { Significance (double } \\
\text { sides) }\end{array}$ \\
\hline Male & 147 & 82.53 & 8.42 & \multirow{2}{*}{$1.9 \leq 2.11^{*}<2.58$} & $0.01<\mathrm{p} \leq 0.05$ \\
\cline { 1 - 5 } Female & 56 & 79.53 & 9.32 & With significant \\
difference \\
\hline
\end{tabular}

Table 3. Test results of experimental class before learning and after learning

\begin{tabular}{|c|c|c|c|c|c|c|}
\hline $\begin{array}{l}\text { Learning } \\
\text { state }\end{array}$ & $\begin{array}{l}\text { Amount of } \\
\text { students (n) }\end{array}$ & $\begin{array}{l}\text { Average scores } \\
(\bar{x})\end{array}$ & $\begin{array}{c}\text { Standard } \\
\text { difference }(\sigma)\end{array}$ & Value of $Z$ & Value of P & $\begin{array}{c}\text { Significance (right } \\
\text { side) }\end{array}$ \\
\hline $\begin{array}{c}\text { After } \\
\text { learning } \\
\end{array}$ & 67 & 90.29 & 6.76 & \multirow{2}{*}{$5.763^{* *}>2.33$} & \multirow{2}{*}{$\mathrm{p} \leq 0.01$} & \multirow{2}{*}{$\begin{array}{c}\text { With extremely } \\
\text { significant difference }\end{array}$} \\
\hline $\begin{array}{c}\text { Before } \\
\text { learning }\end{array}$ & 67 & 82.09 & 7.84 & & & \\
\hline
\end{tabular}

Table 4. Test results of experimental class and control class (1) of freshman (after learning)

\begin{tabular}{|c|c|c|c|c|c|c|}
\hline Class & $\begin{array}{l}\text { Amount } \\
\text { of } \\
\text { students } \\
\text { (n) }\end{array}$ & Average scores & $\begin{array}{c}\text { Standard difference } \\
\qquad(\sigma)\end{array}$ & Value of $Z$ & Value of P & Significance (right side) \\
\hline $\begin{array}{l}\text { Experimental } \\
\text { class }\end{array}$ & 67 & 90.29 & 6.7645 & \multirow{2}{*}{$6.607^{* *} \geq 2.33$} & \multirow{2}{*}{$\mathrm{p} \leq 0.01$} & \multirow{2}{*}{$\begin{array}{l}\text { With extremely } \\
\text { significant difference }\end{array}$} \\
\hline Control class (1) & 136 & 81.40 & 11.2527 & & & \\
\hline
\end{tabular}


Table 5. Test results of experimental class and control class (2) of different grades (after learning)

\begin{tabular}{|c|c|c|c|c|c|c|}
\hline Class & $\begin{array}{c}\text { Amount } \\
\text { of } \\
\text { students } \\
(\mathrm{n})\end{array}$ & $\begin{array}{c}\text { Average scores } \\
(\bar{x})\end{array}$ & $\begin{array}{c}\text { Standard } \\
\text { difference }(\sigma)\end{array}$ & Value of $Z$ & Value of P & Significance (right side) \\
\cline { 1 - 4 } Experimental class & 67 & 90.29 & 6.7645 & \multirow{2}{*}{$6.526^{* *} \geq_{2.33}$} & $\mathrm{p} \leq 0.01$ & $\begin{array}{c}\text { With extremely } \\
\text { significant difference }\end{array}$ \\
\hline Control class (1) & 65 & 77.8846 & 12.3708 &
\end{tabular}

Table 6. Statistical result of seven sorts of error rate

\begin{tabular}{|c|c|c|c|c|c|c|}
\hline $\begin{array}{c}\text { Questions about acting } \\
\text { force and reacting force }\end{array}$ & Question no. & 5 & 10 & 19 & 20 & 31 \\
\hline & Error rate (\%) & 58 & 1 & 49.9 & 15.8 & 14.1 \\
\hline $\begin{array}{c}\text { Questions about levelly } \\
\text { throwing and circular } \\
\text { motion }\end{array}$ & Question no. & 11 & 12 & 18 & 26 & \\
\cline { 2 - 7 } & Error rate (\%) & 33 & 45 & 17 & 9 & 21 \\
\hline $\begin{array}{c}\text { Questions about force } \\
\text { analysis }\end{array}$ & Question no. & 6 & 14 & 24 & 25 & 21 \\
\cline { 2 - 7 } & Error rate (\%) & 2 & 15 & 16 & 17 & 86 \\
\hline $\begin{array}{c}\text { Questions about instant } \\
\text { force and movement }\end{array}$ & Question no. & 2 & 15 & 16 & 17 & 32 \\
\hline
\end{tabular}

